\title{
Role of microRNA-150-5p/SRCIN1 axis in the progression of breast cancer
}

\author{
QINGFU LU, ZHAOJI GUO and HAIXIN QIAN
}

\begin{abstract}
Department of General Surgery, The First Affiliated Hospital of Soochow University, Suzhou, Jiangsu 215006, P.R. China
\end{abstract}
Received June 29, 2018; Accepted November 16, 2018

DOI: $10.3892 / \mathrm{etm} .2019 .7206$

\begin{abstract}
In China, breast cancer is the most commonly occurring cancer in women. MicroRNAs (miRs) are a group of endogenous small non-coding RNAs, which serve a role in many biological processes through the regulation of target genes. In the current study, miR-150-5p expression was significantly up-regulated in breast cancer tissues and cell lines. To investigate the cellular function and underlying molecular mechanism of miR-150-5p in breast cancer, TargetScan7.2 was used to identify miR-150-5p target genes. SRC kinase signaling inhibitor 1 (SRCIN1) was identified as a direct target gene of miR-150-5p and the current study demonstrated that SRCIN1 was negatively regulated by miR-150-5p in breast cancer cells. Furthermore, SRCIN1 expression was significantly down-regulated in breast cancer tissues and cell lines. Taken together, these results demonstrated that there was a negative association between miR-150-5p and SRCIN1 in breast cancer. The CCK- 8 and Transwell assays were used to examine breast cancer cell viability, invasion and migration ability. The current study demonstrated that over-expression of miR-150-5p enhanced breast cancer cell proliferation, invasion and migration. In addition, miR-150-5p over-expression increased the expression of mesenchymal cell markers (vimentin, $\mathrm{N}$-cadherin and $\beta$-catenin) and decreased the expression of epithelial cell markers (E-cadherin and zonula occludens-1). By contrast, miR-150-5p knockdown inhibited breast cancer cell viability, invasion and migration. Additionally, miR-150-5p knockdown decreased the expression of mesenchymal cell markers and increased the expression of epithelial cell markers. Taken together, these results suggest that the miR-150-5p/SRCIN1 axis may be a potential target in the treatment of breast cancer.
\end{abstract}

Correspondence to: Dr Haixin Qian, Department of General Surgery, The First Affiliated Hospital of Soochow University, 188 Shizi Road, Suzhou, Jiangsu 215006, P.R. China

E-mail: qianhx170629@163.com

Key words: microRNA-150-5p, SRC kinase signaling inhibitor 1, breast cancer, epithelial-mesenchymal transition, invasion, migration

\section{Introduction}

Breast cancer is the most frequently diagnosed cancer and the second leading cause of cancer-related mortality among women worldwide (1). The overall incidence of breast cancer worldwide has been increasing since the late 1970s (2). Breast cancer is the second most common cause of brain metastases among solid malignancies and it is estimated to be present at the time of diagnosis of breast cancer in $0.41 \%$ of patients, with $7.56 \%$ of patients presenting with metastatic disease to any site (3). Although progress has been made in the diagnosis and treatment of breast cancer, the survival rate of breast cancer patients remains low (4). It is therefore important to develop novel therapeutic targets for the treatment of breast cancer.

microRNAs (miRNAs or miRs) are a group of endogenous non-coding RNAs 21-23 nucleotides in length, which are present in eukaryotes (5). Increasing evidence suggests that miRNAs can regulate the expression of a broad spectrum of genes resulting in altered cellular processes including cell proliferation, differentiation and apoptosis $(6,7)$. In addition, miRNAs can regulate progression and metastasis in several types of cancer (8-14). Studies have demonstrated that miRNAs can function as either oncogenes or tumor suppressor genes in cancer $(15,16)$. As a result, miRNAs are thought to be promising biomarkers for diagnosis and therapeutic targets in cancer (17-20).

SRC kinase signaling inhibitor 1 (SRCIN1), also known as p140 Cas-associated protein, contains two regions of highly charged amino acids, two proline-rich regions and two coiled-coil domains (21-23). Previous studies have demonstrated that SRCIN1 serves an important role in Src inactivation and it can also act as a tumor suppressor gene in several types of cancer $(24,25)$. A previous study revealed that miR-150 promotes the proliferation and migration of lung cancer cells by targeting SRCIN1 (26). However, the role of miR-150 and its underlying mechanism in breast cancer remains unknown.

Epithelial-mesenchymal transition (EMT) is a biological process, which involves the transformation from a polarized epithelium cell to a mesenchymal cell, which has enhanced migratory capacity and invasiveness $(27,28)$. EMT presents tumor cells with specific stem cell-like characteristics, which include reduced apoptosis and resistance to immunosuppression and senescence (29). These characteristics serve a role in development, however they are also associated with 
tissue healing, organ fibrosis, cancer development and other biological processes.

The aim of the present study was to investigate the cellular function of miR-150 and its underlying mechanism in breast cancer cells.

\section{Materials and methods}

Clinical samples. Triple-negative breast cancer tissue and adjacent healthy tissue samples were collected during biopsies from 30 female (age range, 25-57 years) triple-negative breast cancer patients from the First Affiliated Hospital of Soochow University (Suzhou, China) from January 2015-June 2017. Patients did not receive preoperative radiotherapy or chemotherapy. All tissue samples were immediately flash-frozen in liquid nitrogen and stored at $-80^{\circ} \mathrm{C}$ until further use. The present study was approved by the Ethics Committee of the First Affiliated Hospital of Soochow University, and written informed consent was obtained from each patient.

Cell culture. Human breast epithelial cell MCF10A, and breast cancer cell lines (MCF7, MDA-MB-468, MDA-MB-231 and MDA-MB-157) were purchased from the Shanghai Institute of Life Sciences Cell Resource Centre (Shanghai, China). Cells were cultured in RPMI-1640 or DMEM medium (both Gibco; Thermo Fisher Scientific, Inc., Waltham, MA, USA) supplemented with $10 \%$ fetal bovine serum (FBS; Gibco; Thermo Fisher Scientific, Inc.) and 1\% streptomycin-penicillin mix solution (Sigma-Aldrich; Merck KGaA, Darmstadt, Germany), and maintained at $37^{\circ} \mathrm{C}$ in a $5 \% \mathrm{CO}_{2}$-humidified incubator.

Cell transfection. MDA-MB-468 cells were seeded in 6-well plates at a density of $4 \times 10^{5}$ cells/well. miR-150-5p mimic (5'-UCUCCCAACCCUUGUACCAGUG-3'), mimic control (5'-UUCUCCGAACGUGUCACGUTT-3'), miR-150-5p inhibitor (5'-CACUGGUACAAGGGUUGGGAGA-3') and inhibitor control (5'-CAGUACUUUUGUGUAGUACAA-3') were synthesized by Shanghai GenePharma Co., Ltd. (Shanghai, China). MDA-MB-468 cells were subsequently transfected with $100 \mathrm{nM}$ miR-150-5p mimic, $100 \mathrm{nM}$ mimic control, $100 \mathrm{nM}$ miR-150-5p inhibitor or $100 \mathrm{nM}$ inhibitor control using Lipofectamine ${ }^{\circledR} 3000$ (Invitrogen; Thermo Fisher Scientific, Inc.), according to the manufacturer's protocol. Following 48-h transfection, cells were collected and used for subsequent experimentation. Transfection efficiency was detected using reverse transcription-quantitative polymerase chain reaction (RT-qPCR).

$R T$ - $q P C R$. Total RNA was extracted from cultured cell lines (MCF10A, MCF7, MDA-MB-468, MDA-MB-231 and MDA-MB-157) and tissue samples using TRIzol ${ }^{\circledR}$ reagent (Life Technologies; Thermo Fisher Scientific, Inc.), according to the manufacturer's protocol. Total RNA was reverse transcribed into cDNA using the PrimeScript RT Reagent kit (Takara Bio, Inc., Otsu, Japan), according to the manufacturer's protocol. RNA concentration was detected by NanoDrop ${ }^{\mathrm{TM}} 2000$ spectrophotometer (Thermo Fisher Scientific, Inc.). qPCR was subsequently performed using the SYBR ${ }^{\circledR}$ RT-PCR kit (Takara Bio, Inc.). The following primer sequences were used for the qPCR: miR-150-5p forward, 5'-TCGGCGTCTCCCAACCCT
TGTAC-3' and reverse, 5'-GTCGTATCCAGTGCAGGGTCC GAGGT-3'; SRCIN1 forward, 5'-AGCCCCGACAAAAGC AAAC-3' and reverse, 5'-CCAAAGGAAGTCAATACAGGG ATAG-3'; zonula occludens (ZO)-1 forward, 5'-CCTCTGATC ATTCCACACAGTC-3' and reverse, 5'-TAGACATGCGCT СТTCСТСТCT-3'; E-cadherin forward, 5'-CGAGAGCTA CACGTTCACGG-3' and reverse, 5'-GGGTGTCGAGGG AAAAATAGG-3'; N-cadherin forward, 5'-TTTGATGGA GGTCTCCTAACACC-3' and reverse, 5'-ACGTTTAACACG TTGGAAATGTG-3'; vimentin forward, 5'-GACGCCATC AACACCGAGTT-3' and reverse, 5'-CTTTGTCGTTGGTTA GCTGGT-3'; $\beta$-catenin forward, 5'-AACAGGGTCTGGGAC ATTAGTC-3' and reverse, 5'-CGAAAGCCAATCAAACAC AAAC-3'; U6 forward, 5'-GCTTCGGCAGCACATATACTA AAAT-3' and reverse, 5'-CGCTTCACGAATTTGCGTGTC AT-3'; and GAPDH forward, 5'-CTTTGGTATCGTGGAAGG ACTC-3' and reverse, 5'-GTAGAGGCAGGGATGATGTTC T-3'. The following thermocycling conditions were used for the qPCR: Initial denaturation at $95^{\circ} \mathrm{C}$ for $10 \mathrm{~min} ; 35$ cycles of $95^{\circ} \mathrm{C}$ for $15 \mathrm{sec}$ and $55^{\circ} \mathrm{C}$ for $40 \mathrm{sec}$. Relative expression levels of miR-150, SRCIN1 mRNA and other related genes were quantified using the $2^{-\Delta \Delta \mathrm{Cq}}$ method (30) and normalized to the internal reference genes U6 and GAPDH. All experiments were carried out in triplicate.

Cell viability assay. Cell viability was analyzed using the cell counting kit-8 (CCK-8; cat. no. C0038; Beyotime Institute of Biotechnology, Haimen, China). Logarithmic phase MDA-MB-468 cells were seeded in 96-well plates at a density of $1 \times 10^{4}$ cells/well and incubated at $37^{\circ} \mathrm{C}$ in a $5 \% \mathrm{CO}_{2}$-humidified incubator for $12 \mathrm{~h}$. Following incubation, $10 \mu \mathrm{l}$ CCK-8 reagent was added to each well and cells were incubated for a further $2 \mathrm{~h}$ at $37^{\circ} \mathrm{C}$ in a $5 \% \mathrm{CO}_{2}$-humidified incubator. Cell viability was determined by measuring the absorbance at a wavelength of $490 \mathrm{~nm}$ using a microplate reader.

Western blot analysis. Total protein was extracted from MDA-MB-468 cells using radioimmunoprecipitation assay buffer (Thermo Fisher Scientific, Inc.). Bicinchoninic protein assay kit (Pierce; Thermo Fisher Scientific, Inc.) was used to measure the protein concentration. Proteins (30 $\mu \mathrm{g} / \mathrm{lane})$ were separated via SDS-PAGE on a $10 \%$ gel. The separated proteins were subsequently transferred onto polyvinyl difluoride membranes (EMD Millipore, Billerica, MA, USA) and blocked at room temperature for $2 \mathrm{~h}$ with $5 \%$ skimmed milk in PBS containing $0.1 \%$ Tween ${ }^{\circledR} 20$. The membranes were incubated with primary antibodies against SRCIN1 (1:1,000; cat. no. 3757), E-cadherin (1:1,000; cat. no. 3195), ZO-1 (1:1,000; cat. no. 13663), vimentin (1:1,000; cat. no. 12826), N-cadherin $(1: 1,000$; cat. no. 13116), $\beta$-catenin $(1: 1,000$; cat. no. 25362$)$ or $\beta$-actin (1:1,000; cat. no. 4970; all Cell Signaling Technology, Inc., Danvers, MA, USA) overnight at $4^{\circ} \mathrm{C}$. Following primary incubation, membranes were incubated with horseradish peroxidase-labeled anti-rabbit IgG secondary antibody (1:1,000; cat. no. 7074; Cell Signaling Technology, Inc.) for $2 \mathrm{~h}$ at room temperature. Proteins bands were visualized using the enhanced chemiluminescence super sensitive liquid (cat no. P1010; Applygen Technologies, Inc., Beijing, China) and imaged using the ChemiDoc XRS+ system (Bio-Rad 
A

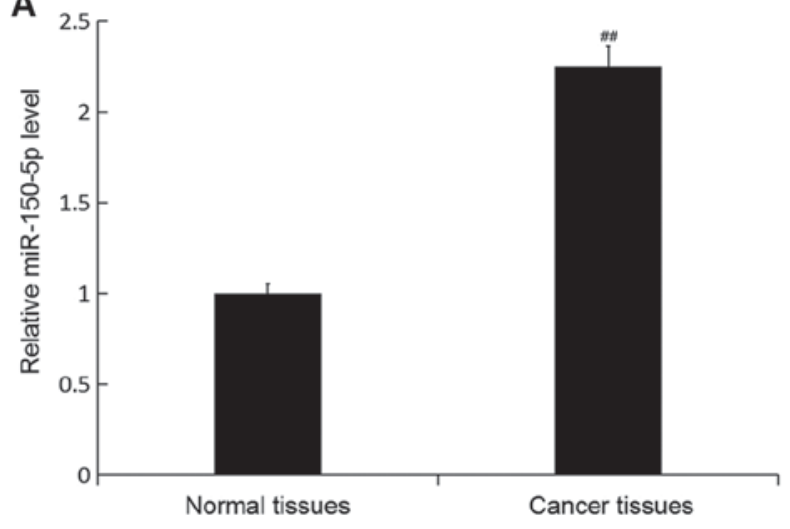

B

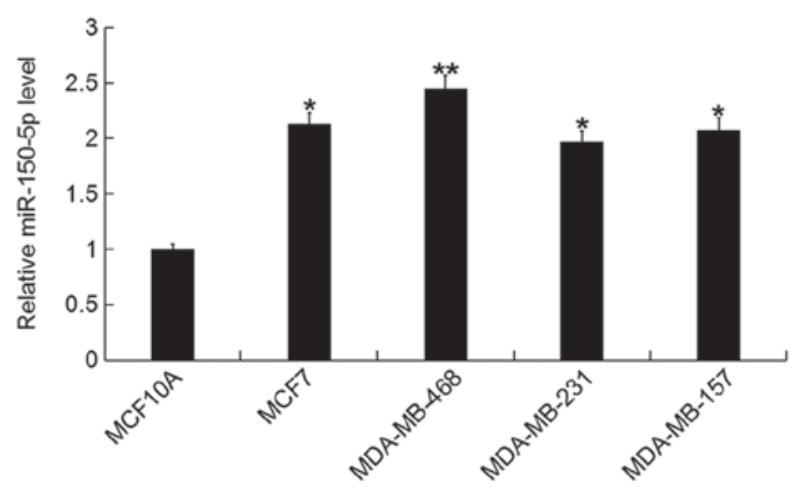

Figure 1. Relative miR-150 expression in breast cancer tissues and cell lines. (A) The relative miR-150-5p expression level was determined by RT-qPCR in breast cancer tissue and adjacent health tissue samples from patients with breast cancer. (B) The relative miR-150-5p expression level was determined by RT-qPCR in breast cancer cell lines MCF7, MDA-MB-468, MDA-MB-231 and MDA-MB-157, and the normal human breast epithelial cell line MCF10A. Data are presented as the mean \pm standard deviation. ${ }^{\# \#} \mathrm{P}<0.01$ vs. Normal tissues; ${ }^{*} \mathrm{P}<0.05$ and ${ }^{* *} \mathrm{P}<0.01$ vs. the MCF10A cell line. miR, microRNA; RT-qPCR, reverse transcription-quantitative polymerase chain reaction.

Laboratories, Inc., Hercules, CA, USA). Protein expression was quantified using Gel-Pro Analyzer software (version 6.3; Media Cybernetics, Inc., Rockville, MD, USA).

Transwell assay. Cell invasion and migration was examined using the Transwell assay using Transwell inserts (Corning, Inc., Corning, NY, USA) with or without Matrigel ${ }^{\circledR}$ (BD Biosciences, San Jose, CA, USA). Following transfection, MDA-MB-468 cells ( $1 \times 10^{4}$ cells/well) in $100 \mu \mathrm{l}$ serum-free medium added to the upper chamber of the Transwell insert, whereas $500 \mu \mathrm{l}$ medium supplemented with $10 \%$ FBS was added to the lower chamber and the plates were incubated at $37^{\circ} \mathrm{C}$ for $48 \mathrm{~h}$. The invasive and migratory cells were fixed with methanol for $20 \mathrm{~min}$, and then stained with $0.1 \%$ crystal violet for $20 \mathrm{~min}$ at $37^{\circ} \mathrm{C}$. The total number of migratory and invasive cells on the underside of the membrane was counted using five randomly selected visual fields under an inverted light microscope at a magnification of x200.

Dual-luciferase reporter assay. TargetScan 7.2 (http://www. targetscan.org/vert_72/) was used to analyze the potential targets of miR-150-5p, and it was determined that the binding site of miR-150-5p corresponds to that of SRCIN1. To confirm the direct binding between miR-150-5p and SRCIN1, the wild type (WT-SRCIN1) and mutant (MUT-SRCIN1) 3'UTR of SRCIN1 was cloned into the pmiR-RB-Report ${ }^{\mathrm{TM}}$ luciferase reporter vector plasmids (Guangzhou RiboBio Co., Ltd., Guangzhou, China). Cells $\left(5 \times 10^{4}\right.$ cells/well) were seeded into 24 -well plates, and co-transfected with $100 \mathrm{nM}$ miR-150-5p mimic or $100 \mathrm{nM}$ mimic control and the WT-SRCIN1 (40 ng) or MUT-SRCIN1 (40 ng) plasmids using Lipofectamine ${ }^{\circledR} 3000$ (Invitrogen; Thermo Fisher Scientific, Inc.) for $48 \mathrm{~h}$. Following 48-h transfection, relative luciferase activities were detected using a Dual-Luciferase Reporter assay system (Promega Corporation, Madison, WI, USA), according to the manufacturer's protocol. Firefly luciferase activity was normalized to Renilla luciferase activity.

Statistical analysis. Data are presented as the mean \pm standard deviation. All statistical analyses were performed using SPSS software (version 17.0; SPSS, Inc., Chicago, IL, USA). The statistical significance of differences between two groups was analyzed using both paired and unpaired Student's t-test. One-way analysis of variance followed by Tukey's post hoc test was used to analyze differences among multiple groups. All experiments were repeated three times. $\mathrm{P}<0.05$ was considered to indicate a statistically significant difference.

\section{Results}

miR-150-5p expression in breast cancer. The expression level of miR-150-5p was detected by RT-qPCR in breast cancer tissue samples and cell lines. The expression level of miR-150 was significantly increased in breast cancer tissue compared with adjacent healthy tissue samples (Fig. 1A). In addition, the expression level of miR-150-5p was significantly increased in all breast cancer cell lines (MCF7, MDA-MB-468, MDA-MB-231 and MDA-MB-157) compared with the normal human breast epithelial cell line MCF10A (Fig. 1B). The greatest increase was observed in the MDA-MB-468 cell line, and therefore these cells were selected for all subsequent experimentation.

SRCIN1 is a direct target of miR-150-5p. SRCIN1, an inhibitor of Src activity and downstream signaling (23), was identified as a putative target gene of miR-150-5p. TargetScan was used to predict the miR-150-5p binding site in the 3'UTR of SRCIN1 (Fig. 2A). Luciferase reporter assays were used to validate the direct interaction between miR-150-5p and SRCIN1. The current study demonstrated that miR-150-5p overexpression significantly decreased SRCIN1-WT luciferase activity compared with SRCIN1-MUT, which had no marked effect on luciferase activity (Fig. 2B). The results suggest that SRCIN1 is a direct target gene of miR-150-5p.

To investigate whether miR-150-5p regulates endogenous SRCIN1 expression in breast cancer, SRCIN1 expression was analyzed in MDA-MB-468 cells following 48-h transfection with miR-150-5p mimic, mimic control, miR-150-5p inhibitor or inhibitor control. The relative miR-150-5p expression level was significantly increased, whilst the SRCIN1 mRNA expression level was significantly decreased in MDA-MB-468 cells 
A Position 830-837 of SRCIN1 $3^{\prime}$ UTR $5^{\prime}$.... AUCCCGCGACACUCCCUTCCGACA. .

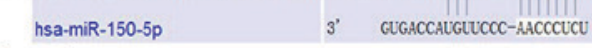

B
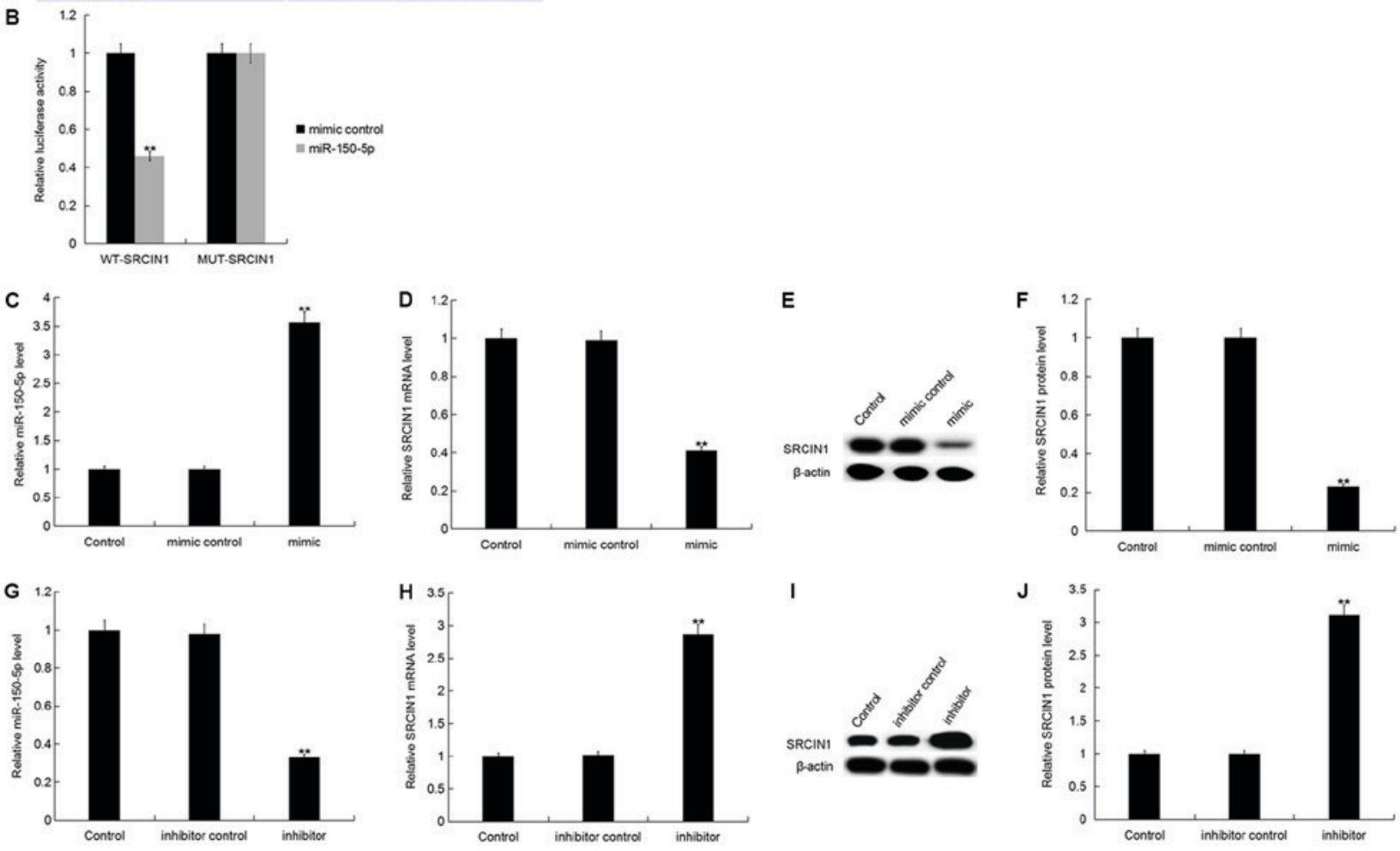

I

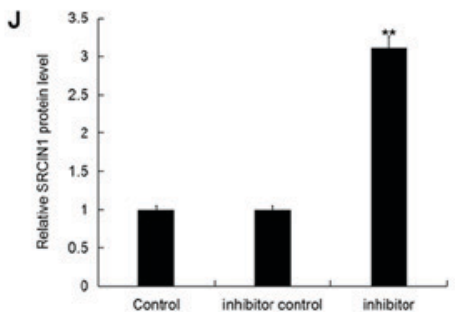

Figure 2. SRCIN1 is a direct target of miR-150-5p. (A) Bioinformatics analysis was used to predict the miR-150-5p binding site in the 3'-UTR of SRCIN1. (B) Luciferase reporter assays were performed in MDA-MB-468 cells following co-transfection with luciferase reporter plasmids containing SRCIN1-3'UTR-WT or SRCIN1-3'UTR-MUT and miR-150-5p mimic or mimic control. (C) The relative miR-150-5p expression level was determined by RT-qPCR in MDA-MB-468 cells following transfection with miR-150-5p mimic and mimic control. (D) The relative SRCIN1 expression level was determined by RT-qPCR in MDA-MB-468 cells following transfection with miR-150-5p mimic and mimic control. (E) The relative protein expression level of SRCIN1 was determined by western blot analysis in MDA-MB-468 cells following transfection with miR-150-5p mimic and mimic control. (F) Quantification of SRCIN1 protein expression. (G) The relative miR-150-5p expression level was determined by RT-qPCR in MDA-MB-468 cells following transfection with miR-150-5p inhibitor and inhibitor control. (H) The relative SRCIN1 expression level was determined by RT-qPCR in MDA-MB-468 cells following transfection with miR-150-5p inhibitor and inhibitor control. (I) The relative protein expression level of SRCIN1 was determined by western blot analysis in MDA-MB-468 cells following transfection with miR-150-5p inhibitor and inhibitor control. (J) Quantification of SRCIN1 protein expression. ${ }^{* *} \mathrm{P}<0.01$ vs. Control. SRCIN1, SRC kinase signaling inhibitor 1; miR, microRNA; UTR, untranslated region; WT, wild-type; MUT, mutant; RT-qPCR, reverse transcription-quantitative polymerase chain reaction.

following transfection with miR-150-5p mimic compared with the control (Fig. 2C and D). In addition, the protein expression level of SRCIN1 was significantly decreased in MDA-MB-468 cells following transfection with miR-150-5p mimic compared with the control (Fig. 2E and F).

Furthermore, the relative miR-150-5p expression level was significantly decreased, whilst the SRCIN1 mRNA expression level was significantly increased in MDA-MB-468 cells following transfection with miR-150-5p inhibitor compared with the control (Fig. $2 \mathrm{G}$ and $\mathrm{H}$ ). In addition, the protein expression level of SRCIN1 was significantly increased in MDA-MB-468 cells following transfection with miR-150-5p inhibitor compared with the control (Fig. 2I and J).

SRCIN1 expression in breast cancer. To further investigate the association between miR-150-5p and SRCIN1, the expression level of SRCIN1 was detected by RT-qPCR in breast cancer tissue samples and cell lines. The mRNA expression level of SRCIN1 was significantly decreased in breast cancer tissue compared with adjacent healthy tissue samples (Fig. 3A).
In addition, the mRNA expression level of SRCIN1 was significantly decreased in all breast cancer cell lines (MCF7, MDA-MB-468, MDA-MB-231 and MDA-MB-157) compared with the normal human breast epithelial cell line MCF10A (Fig. 3B). Furthermore, the protein expression level of SRCIN1 was significantly decreased in each breast cancer cell line compared with MCF10A (Fig. 3C and D). The greatest decrease was observed in the MDA-MB-468 cell line, and therefore these were selected for all subsequent experimentation.

Effect of miR-150-5p on breast cancer cell viability, migration and invasion. To investigate the role of miR-150-5p in breast cancer, the CCK-8 and Transwell assays were used to examine the effect of miR-150-5p on the cell viability, invasion and migration ability of breast cancer cells following 48-h transfection with miR-150-5p mimic, mimic control, miR-150-5p inhibitor or inhibitor control. Cell viability, invasion and migration were significantly increased in MDA-MB-468 cells following transfection with miR-150-5p mimic compared with the control (Fig. 4A-C). By contrast, the cell viability, invasion 

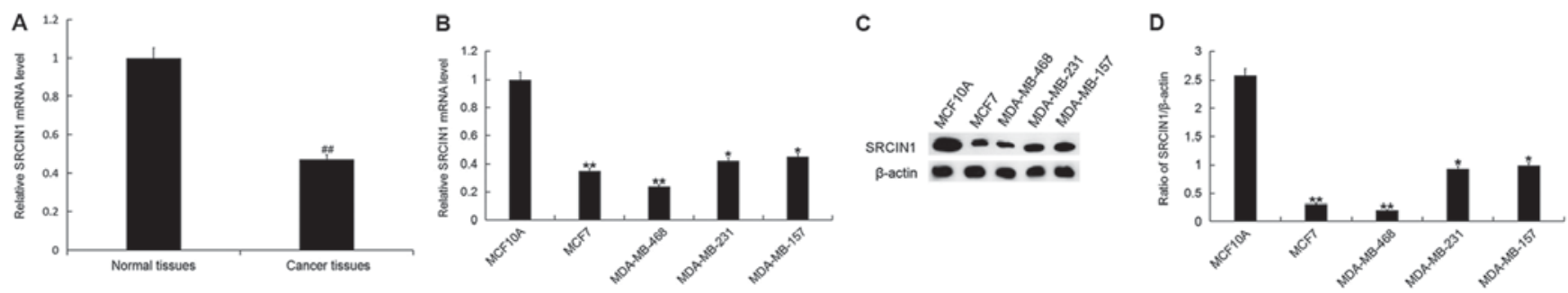

Figure 3. SRCIN1 expression in breast cancer tissue and cells. (A) The relative SRCIN1 mRNA expression level was determined by RT-qPCR in breast cancer tissue and adjacent healthy tissue samples from patients with breast cancer. (B) The relative SRCIN1 mRNA expression level was determined by RT-qPCR in breast cancer cell lines MCF7, MDA-MB-468, MDA-MB-231 and MDA-MB-157, and the normal human breast epithelial cell line MCF10A. (C) The relative protein expression level of SRCIN1 was determined by western blot analysis in breast cancer cell lines MCF7, MDA-MB-468, MDA-MB-231 and MDA-MB-157, and the normal human breast epithelial cell line MCF10A. (D) Quantification of SRCIN1 protein expression. Data are presented as the mean \pm standard deviation. ${ }^{\# \#} \mathrm{P}<0.01$ vs. Normal tissues; ${ }^{*} \mathrm{P}<0.05,{ }^{* *} \mathrm{P}<0.01$ vs. the MCF10A cell line. SRCIN1, SRC kinase signaling inhibitor 1 ; miR, microRNA; RT-qPCR, reverse transcription-quantitative polymerase chain reaction.
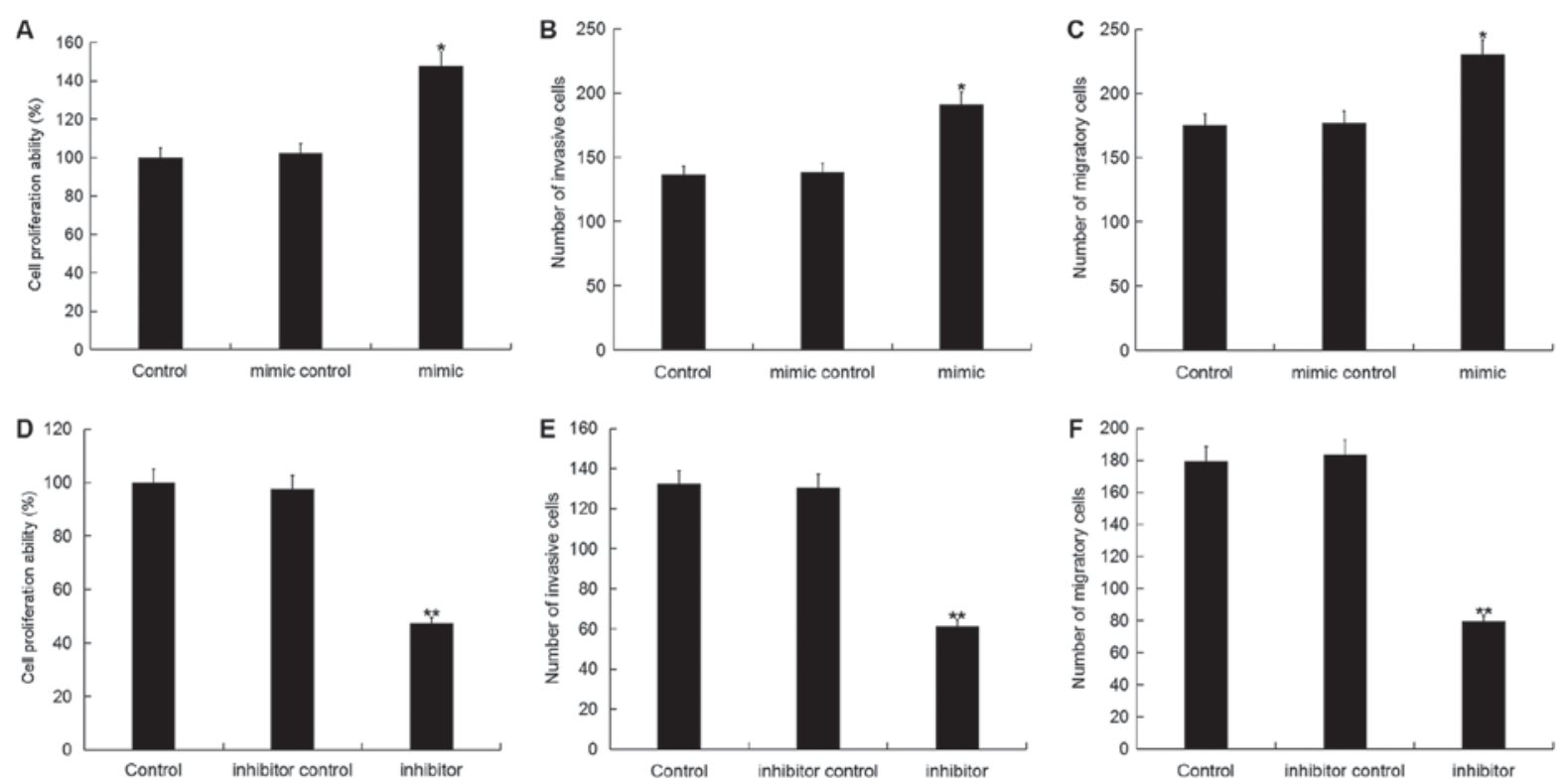

Figure 4. Effect of miR-150-5p on breast cancer cell proliferation, invasion and migration. (A) Cell proliferation, (B) invasion and (C) migration were examined in MDA-MB-468 cells following 48-h transfection with miR-150-5p mimic and mimic control. (D) Cell proliferation, (E) invasion and (F) migration were examined in MDA-MB-468 cells following 48-h transfection with miR-150-5p inhibitor and inhibitor control. Data are presented as the mean \pm standard deviation. ${ }^{*} \mathrm{P}<0.05$ and ${ }^{* *} \mathrm{P}<0.01$ vs. Control. miR, microRNA.

and migration were significantly decreased in MDA-MB-468 cells following transfection with miR-150-5p inhibitor compared with the control (Fig. 4D-F). These results suggest that miR-150-5p up-regulation can promote cell invasion and migration, whilst miR-150-5p down-regulation can reduce cell invasion and migration.

Effect of miR-150-5p on EMT in breast cancer cells. To investigate the effect of miR-150-5p on EMT in breast cancer, the expression of specific EMT markers including epithelial cell markers (E-cadherin, ZO-1) and interstitial cell markers ( $\mathrm{N}$-cadherin, vimentin, $\beta$-catenin), were analyzed in MDA-MB-468 cells following transfection with miR-150-5p mimic, mimic control, miR-150-5p inhibitor or inhibitor control. The protein expression level of $\mathrm{N}$-cadherin, vimentin and $\beta$-catenin were significantly increased, whilst E-cadherin and ZO-1 protein expression were significantly decreased in MDA-MB-468 cells following transfection with miR-150-5p mimic compared with the control (Fig. 5A-F). Additionally, similar results were obtained following mRNA expression analysis (Fig. 5G-K).

Furthermore, the protein expression level of N-cadherin, vimentin and $\beta$-catenin were significantly decreased, whilst E-cadherin and ZO-1 protein expression were significantly increased in MDA-MB-468 cells following transfection with miR-150-5p inhibitor compared with the control (Fig. 6A-F). Additionally, similar results were obtained following mRNA expression analysis (Fig. 6G-K).

\section{Discussion}

Breast cancer is currently a major health threat to women worldwide. In China, there were $\sim 268,600$ new breast cancer cases and 69,500 breast cancer-related mortalities in women in 2015 (31). Although there are numerous drug combinations and treatment regimens, patients with advanced breast cancer develop resistance to treatment. Resistance to chemotherapy is a major obstacle to the effective treatment of breast cancer (32). 
A
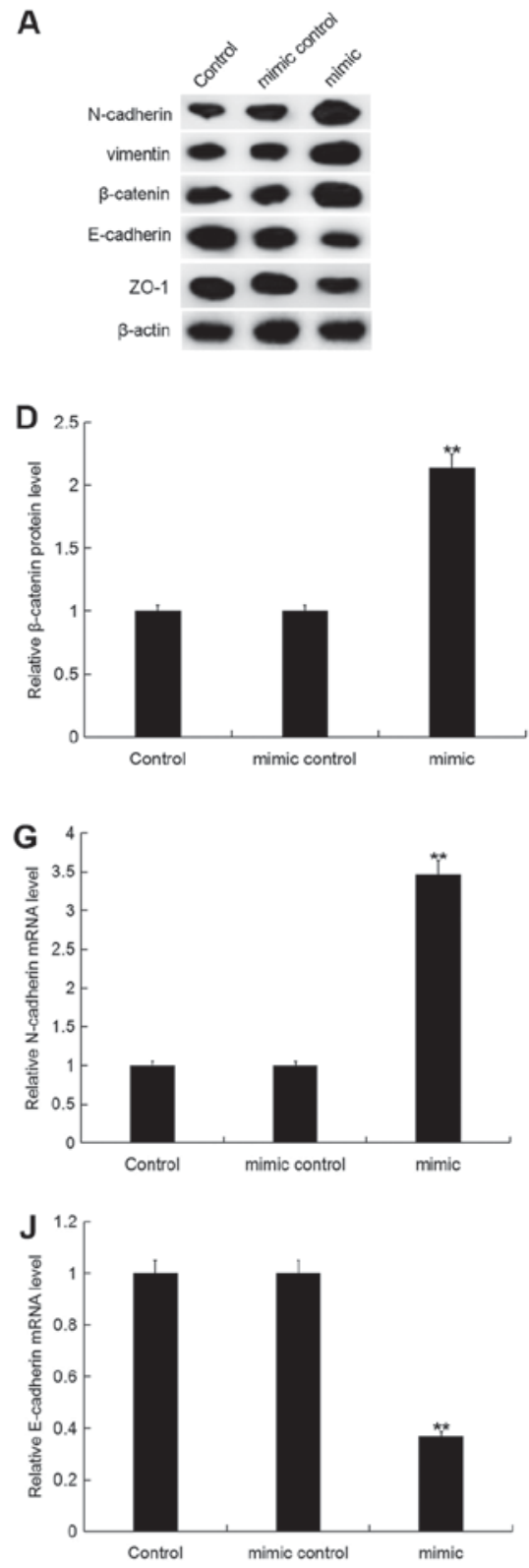
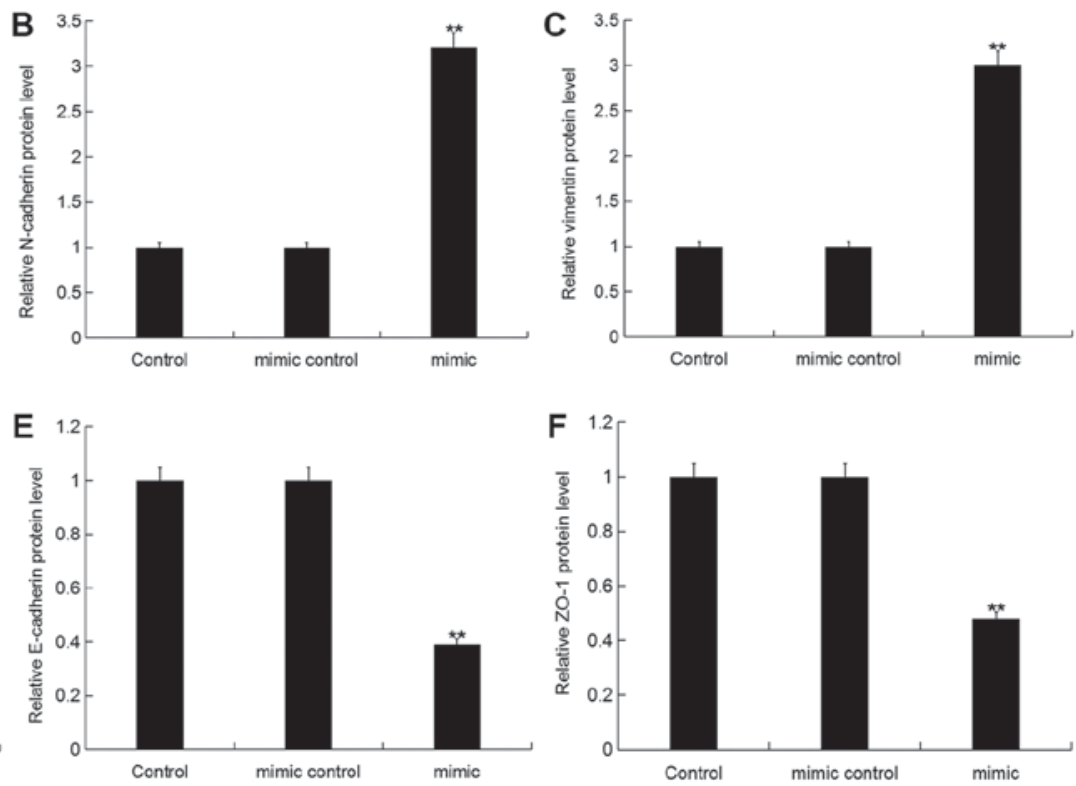

H
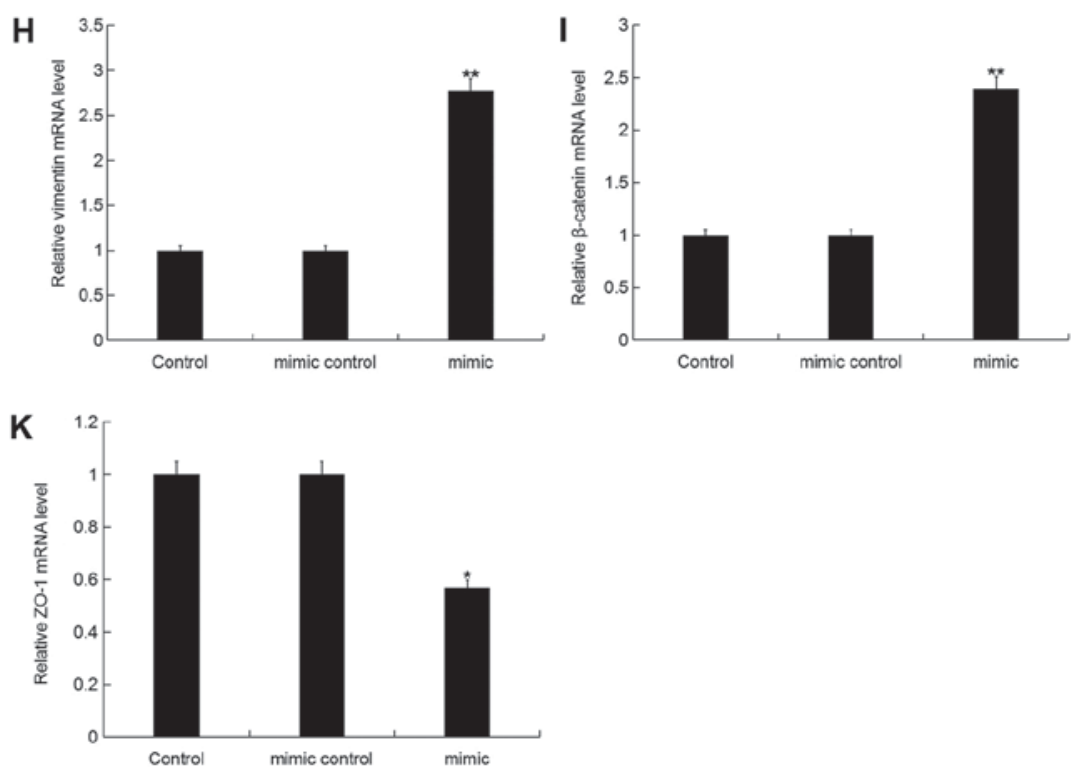

Figure 5. Effect of miR-150-5p on epithelial-mesenchymal transition in breast cancer cells. (A) The relative protein expression level of N-cadherin, vimentin, $\beta$-catenin, E-cadherin and ZO-1 were determined by western blot analysis in MDA-MB-468 cells following 48-h transfection with miR-150-5p mimic and mimic control. Quantification of (B) N-cadherin, (C) vimentin, (D) $\beta$-catenin, (E) E-cadherin and (F) ZO-1 protein expression. The relative (G) N-cadherin, (H) vimentin, (I) $\beta$-catenin, (J) E-cadherin and (K) ZO-1 mRNA expression level was determined by RT-qPCR in MDA-MB-468 cells following 48-h transfection with miR-150-5p mimic and mimic control. Data are presented as the mean \pm standard deviation. ${ }^{*} \mathrm{P}<0.05$ and ${ }^{* * *} \mathrm{P}<0.01$ vs. Control. miR, microRNA; ZO-1, zonula occludens-1; RT-qPCR, reverse transcription-quantitative polymerase chain reaction.

Therefore, it is necessary to develop a novel treatment strategy for breast cancer with an enhanced therapeutic effect and decreased drug resistance.

Several studies have demonstrated that miRNAs serve a role in the development and progression of several types of cancer (8-14). Previous studies demonstrated that miR-150 expression was decreased in several types of human cancer, including lymphoma, liver, colon and bladder cancer (33-38). miR-150, as a tumor suppressor gene, could inhibit the proliferation, migration and invasion of cancer cells via several mechanisms; for example, through regulating the expression of oncogenes or tumor suppressor genes and cell cycle checkpoints (33-38). A previous study indicated that miRNA-150 inhibits the proliferation and tumorigenicity of nasopharyngeal carcinoma cells (5). By contrast, several studies have demonstrated that miR-150 was up-regulated in several types of cancer, including chronic lymphocytic leukemia (39), non-small cell lung cancer (40) and gastric cancer (41). As an oncogene, miR-150 could promote cancer cell proliferation and metastasis $(40,41,26)$. Cao et al $(26)$ revealed that miR-150 was highly expressed in lung cancer cells, and miR-150 overexpression could promote lung cancer cell proliferation. Whether miR-150 is an oncogene or a tumor suppressor gene mostly depends on the type of cancer, as miR-150 serves a different role in different types of cancer (42). However, the role of miR-150 and its underlying mechanism in breast cancer remains unknown.

The current study demonstrated that miR-150-5p expression is up-regulated in triple-negative breast cancer tissue 
A
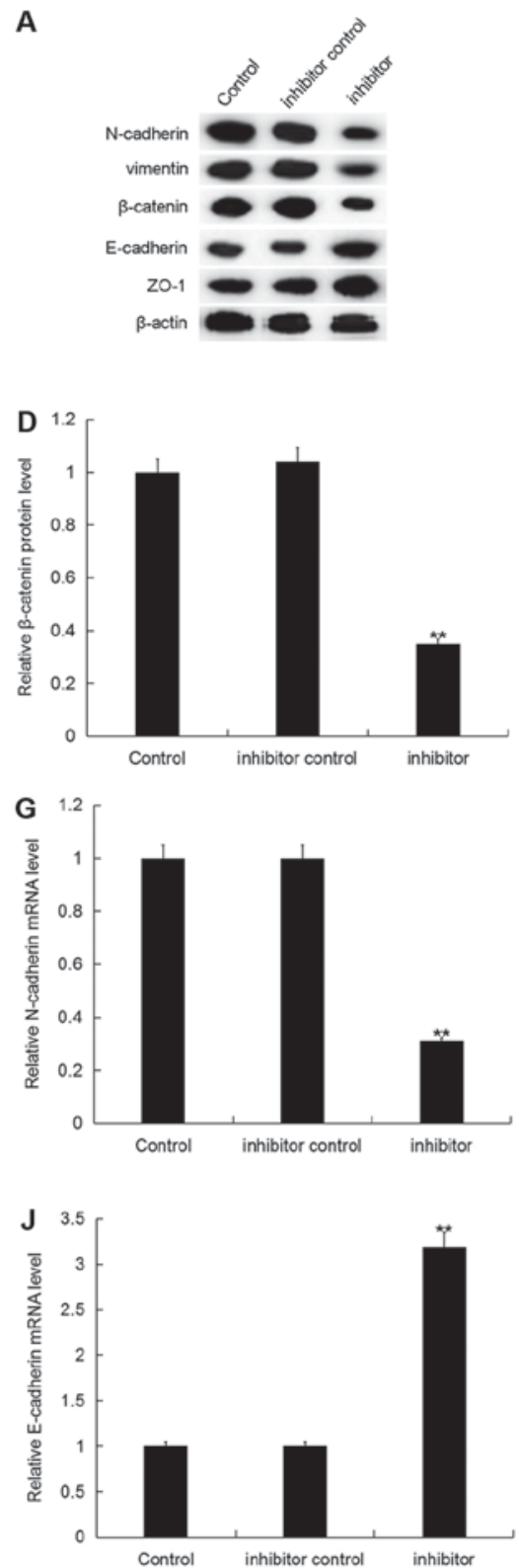

B

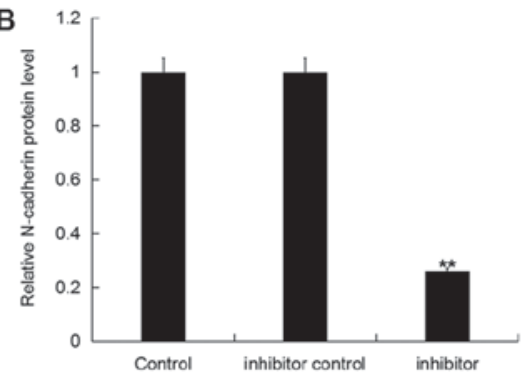

E

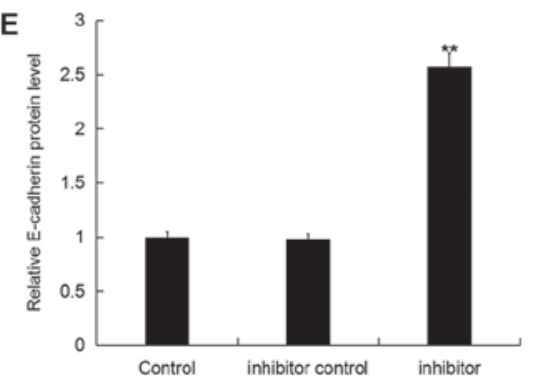

H

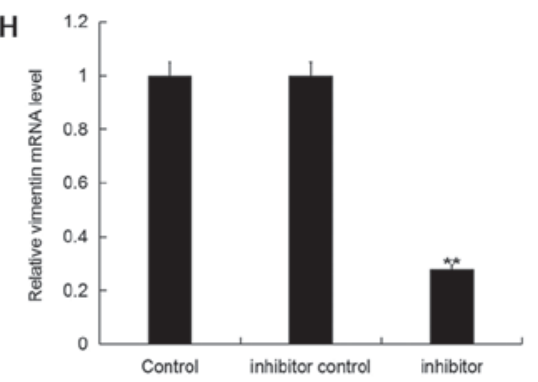

K

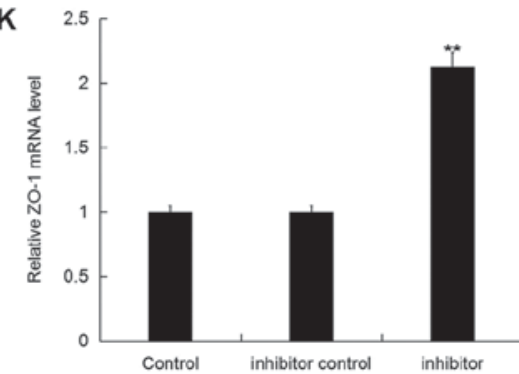

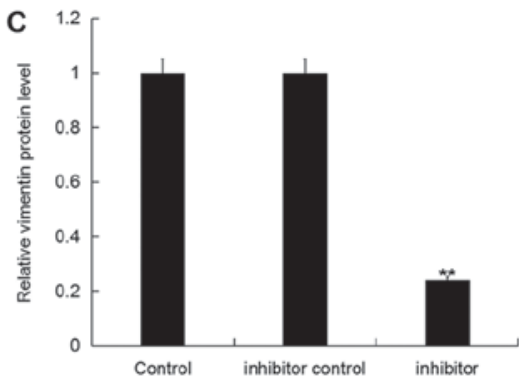

$\mathbf{F}$
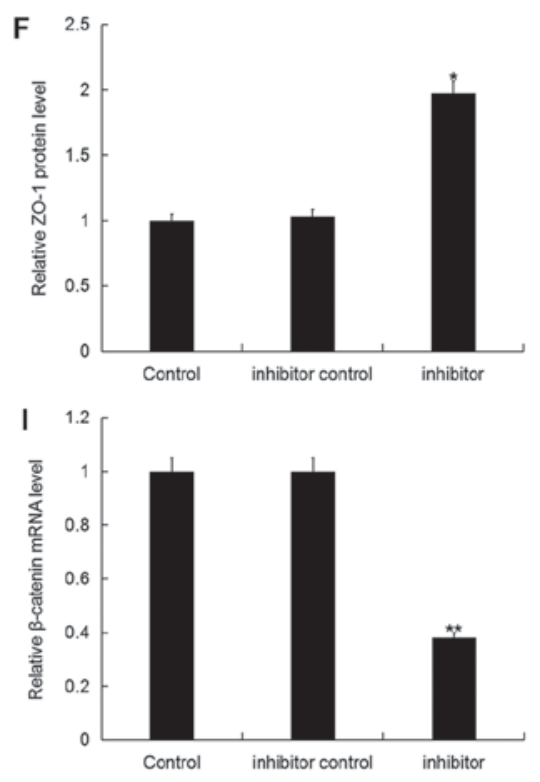

Figure 6. Effect of miR-150-5p inhibition on epithelial-mesenchymal transition in breast cancer cells. (A) The relative protein expression level of N-cadherin, vimentin, $\beta$-catenin, E-cadherin and ZO-1 were determined by western blot analysis in MDA-MB-468 cells following 48-h transfection with miR-150-5p inhibitor and inhibitor control. Quantification of (B) N-cadherin, (C) vimentin, (D) $\beta$-catenin, (E) E-cadherin and (F) ZO-1 protein expression. The relative (G) N-cadherin, (H) vimentin, (I) $\beta$-catenin, (J) E-cadherin and (K) ZO-1 mRNA expression level was determined by RT-qPCR in MDA-MB-468 cells following 48-h transfection with miR-150-5p inhibitor and inhibitor control. Data are presented as the mean \pm standard deviation. ${ }^{*} \mathrm{P}<0.05$ and ${ }^{* *} \mathrm{P}<0.01$ vs. Control. miR, microRNA; ZO-1, tight junction protein ZO-1; RT-qPCR, reverse transcription-quantitative polymerase chain reaction.

compared with adjacent healthy tissue samples. In addition, the level of miR-150-5p expression was significantly increased in all breast cancer cell lines (MCF7, MDA-MB-468, MDA-MB-231 and MDA-MB-157) compared with the normal human breast epithelial cell line MCF10A, and the greatest increase was observed in MDA-MB-468 cells. Therefore, the triple negative breast cancer cell line MDA-MB-468 for chosen for all subsequent experimentation. Further analysis revealed that the miR-150-5p mimic significantly increased MDA-MB-468 cell viability, invasion and migration ability. By contrast, the miR-150-5p inhibitor attenuated MDA-MB-468 cell viability, invasion and migration ability. These results suggest that miR-150-5p may be acting as an oncogene in breast cancer.
To further investigate the underlying mechanism of miR-150-5p in breast cancer, bioinformatics analysis was used to predict SRCIN1 as a direct target of miR-150-5p. Src is a non-receptor tyrosine kinase, which is mainly expressed in brain, testis and certain epithelial-rich organs including the mammary glands, lungs, colon and kidneys (43). Yang et al (44) recently reported that SRCIN1 expression was significantly decreased in breast cancer tissues and cells, and that SRCIN1 expression was inversely correlated with miR-346 expression. Di Stefano et al indicated that SRCIN1 overexpression inhibited cell proliferation, migration and invasion in breast cancer cells (23). Furthermore, a previous study demonstrated that there was a negative correlation between SRCIN1 and breast cancer (22). Consistent with previous studies, the current study 
demonstrated that SRCIN1 was significantly down-regulated in both breast cancer tissues and cell lines. In addition, SRCIN1 was identified as a direct target gene of miR-150-5p, and SRCIN1 was negatively regulated by miR-150-5p.

To further confirm the role of miR-150-5p in promoting the invasion and migration of breast cancer cells, the expression of EMT-related proteins was analyzed. The results demonstrated that miR-150-5p significantly increased the expression of mesenchymal cell markers and reduced the expression of epithelial cell markers at both the protein and mRNA level.

In conclusion, the results of the current study demonstrated that miR-150-5p may promote cell viability, invasion and migration by directly targeting SRCIN1 and thereby identifying a potentially novel therapeutic target in the treatment of breast cancer.

\section{Acknowledgements}

Not applicable.

\section{Funding}

No funding received.

\section{Availability of data and materials}

All data sets used and/or generated during the current study are available from the corresponding author on reasonable request.

\section{Authors' contributions}

QL designed the study. QL and ZG analyzed the data and prepared the manuscript. HQ analyzed the data. All authors read and approved the final manuscript.

\section{Ethics approval and consent to participate}

The present study was approved by the Ethics Committee of the First Affiliated Hospital of Soochow University, and written informed consent was obtained from each patient.

\section{Patient consent for publication}

Not applicable.

\section{Competing interests}

The authors declare that they have no competing interests.

\section{References}

1. DeSantis C, Ma J, Bryan L and Jemal A: Breast cancer statistics, 2013. CA Cancer J Clin 64: 52-62, 2014.

2. Althuis MD, Dozier JM, Anderson WF, Devesa SS and Brinton LA: Global trends in breast cancer incidence and mortality 1973-1997. Int J Epidemiol 34: 405-412, 2005.

3. Martin AM, Cagney DN, Catalano PJ, Warren LE, Bellon JR, Punglia RS, Claus EB, Lee EQ, Wen PY, Haas-Kogan DA, et al: Brain metastases in newly diagnosed breast cancer: A population-based study. JAMA Oncol 3: 1069-1077, 2017.
4. de la Mare JA, Contu L, Hunter MC, Moyo B, Sterrenberg JN, Dhanani KC, Mutsvunguma LZ and Edkins AL: Breast cancer: Current developments in molecular approaches to diagnosis and treatment. Recent Pat Anticancer Drug Discov 9: 153-175, 2014.

5. Li X, Liu F, Lin B, Luo H, Liu M, Wu J, Li C, Li R, Zhang X, Zhou $\mathrm{K}$ and Ren D: miR-150 inhibits proliferation and tumorigenicity via retarding G1/S phase transition in nasopharyngeal carcinoma. Int J Oncol: 10 Mar, 2017 (Epub ahead of print).

6. Khew-Goodall Y and Goodall GJ: Myc-modulated miR-9 makes more metastases. Nat Cell Biol 12: 209-211, 2010.

7. Chen K and Rajewsky N: The evolution of gene regulation by transcription factors and microRNAs. Nat Rev Genet 8: 93-103, 2007.

8. Ren D, Wang M, Guo W, Huang S, Wang Z, Zhao X, Du H, Song L and Peng X: Double-negative feedback loop between ZEB2 and miR-145 regulates epithelial-mesenchymal transition and stem cell properties in prostate cancer cells. Cell Tissue Res 358: 763-778, 2014

9. Baranwal S and Alahari SK: miRNA control of tumor cell invasion and metastasis. Int J Cancer 126: 1283-1290, 2010.

10. Ren D, Wang M, Guo W, Zhao X, Tu X, Huang S, Zou X and Peng X: Wild-type p53 suppresses the epithelial-mesenchymal transition and stemness in PC-3 prostate cancer cells by modulating miR-145. Int J Oncol 42: 1473-1481, 2013.

11. Garzon R, Calin GA and Croce CM: MicroRNAs in Cancer. Annu Rev Med 60: 167-179, 2009.

12. Zhang X, Liu J, Zang D, Wu S, Liu A, Zhu J, Wu G, Li J and Jiang L: Upregulation of miR-572 transcriptionally suppresses SOCS1 and p21 and contributes to human ovarian cancer progression. Oncotarget 6: 15180-15193, 2015.

13. Wang M, Ren D, Guo W, Wang Z, Huang S, Du H, Song L and Peng X: Loss of miR-100 enhances migration, invasion, epithelial-mesenchymal transition and stemness properties in prostate cancer cells through targeting Argonaute 2. Int J Oncol 45: 362-372, 2014

14. Huang S, Guo W, Tang Y, Ren D, Zou X and Peng X: miR-143 and miR-145 inhibit stem cell characteristics of PC-3 prostate cancer cells. Oncol Rep 28: 1831-1837, 2012.

15. Wang D, Qiu C, Zhang H, Wang J, Cui Q and Yin Y: Human microRNA oncogenes and tumor suppressors show significantly different biological patterns: From functions to targets. PLoS One 5: pii: e13067, 2010.

16. Esquela-Kerscher A and Slack FJ: Oncomirs-microRNAs with a role in cancer. Nat Rev Cancer 6: 259-269, 2006.

17. Cheng CJ, Bahal R, Babar IA, Pincus Z, Barrera F, Liu C, Svoronos A, Braddock DT, Glazer PM, Engelman DM, et al: MicroRNA silencing for cancer therapy targeted to the tumour microenvironment. Nature 518: 107-110, 2015.

18. Calin GA, Ferracin M, Cimmino A, Di Leva G, Shimizu M, Wojcik SE, Iorio MV, Visone R, Sever NI, Fabbri M, et al: A MicroRNA signature associated with prognosis and progression in chronic lymphocytic leukemia. N Engl J Med 353: 1793-1801, 2005.

19. Volinia S, Calin GA, Liu CG, Ambs S, Cimmino A, Petrocca F, Visone R, Iorio M, Roldo C, Ferracin M, et al: A microRNA expression signature of human solid tumors defines cancer gene targets. Proc Natl Acad Sci USA 103: 2257-2261, 2006.

20. Zhang L, Ye Y, Tu H, Hildebrandt MA, Zhao L, Heymach JV, Roth JA and Wu X: MicroRNA-related genetic variants in iron regulatory genes, dietary iron intake, microRNAs and lung cancer risk. Ann Oncol 28: 1124-1129, 2017.

21. Di Stefano P, Leal MP, Tornillo G, Bisaro B, Repetto D, Pincini A, Santopietro E, Sharma N, Turco E, Cabodi S and Defilippi P: The adaptor proteins p140CAP and p130CAS as molecular hubs in cell migration and invasion of cancer cells. Am J Cancer Res 1: 663-673, 2011.

22. Damiano L, Di Stefano P, Camacho Leal MP, Barba M, Mainiero F, Cabodi S, Tordella L, Sapino A, Castellano I, Canel M, et al: p140Cap dual regulation of E-cadherin/EGFR cross-talk and Ras signalling in tumour cell scatter and proliferation. Oncogene 29: 3677-3690, 2010.

23. Di Stefano P, Damiano L, Cabodi S, Aramu S, Tordella L, Praduroux A, Piva R, Cavallo F, Forni G, Silengo L, et al: p140Cap protein suppresses tumour cell properties, regulating Csk and Src kinase activity. EMBO J 26: 2843-2855, 2007.

24. Sun W, Wang X, Li J, You C, Lu P, Feng H, Kong Y, Zhang H, Liu Y, Jiao R, et al: MicroRNA-181a promotes angiogenesis in colorectal cancer by targeting SRCIN1 to promote the SRC/VEGF signaling pathway. Cell Death Dis 9: 438, 2018. 
25. Chen R, Liao JY, Huang J, Chen WL, Ma XJ and Luo XD Downregulation of SRC kinase signaling inhibitor 1 (SRCIN1) expression by MicroRNA-32 promotes proliferation and epithelial-mesenchymal transition in human liver cancer cells. Oncol Res 26: 573-579, 2018.

26. Cao M, Hou D, Liang H, Gong F, Wang Y, Yan X, Jiang X, Wang C, Zhang J, Zen K, et al: miR-150 promotes the proliferation and migration of lung cancer cells by targeting SRC kinase signalling inhibitor 1. Eur J Cancer 50: 1013-1024, 2014.

27. Chen T, You Y, Jiang H and Wang ZZ: Epithelial-mesenchymal transition (EMT): A biological process in the development, stem cell differentiation, and tumorigenesis. J Cell Physiol 232: 3261-3272, 2017.

28. Shenoy AK, Jin Y,Luo H, Tang M,Pampo C, Shao R, Siemann DW, Wu L, Heldermon CD, Law BK, et al: Epithelial-to-mesenchymal transition confers pericyte properties on cancer cells. J Clin Invest 126: 4174-4186, 2016.

29. Mani SA, Guo W, Liao MJ, Eaton EN, Ayyanan A, Zhou AY, Brooks M, Reinhard F, Zhang CC, Shipitsin M, et al: The epithelial-mesenchymal transition generates cells with properties of stem cells. Cell 133: 704-715, 2008.

30. Livak KJ and Schmittgen TD: Analysis of relative gene expression data using real-time quantitative PCR and the 2(-Delta Delta C(T)) method. Methods 25: 402-408, 2001

31. Chen W, Zheng R, Baade PD, Zhang S, Zeng H, Bray F, Jemal A, Yu XQ and He J: Cancer statistics in China, 2015. CA Cancer J Clin 66: 115-132, 2016.

32. DeMichele A, Yee D and Esserman L: Mechanisms of resistance to neoadjuvant chemotherapy in breast cancer. N Engl J Med 377: 2287-2289, 2017

33. Watanabe A, Tagawa H, Yamashita J, Teshima K, Nara M, Iwamoto K, Kume M, Kameoka Y, Takahashi N, Nakagawa T, et al: The role of microRNA-150 as a tumor suppressor in malignant lymphoma. Leukemia 25: 1324-1334, 2011.

34. Sun W, Zhang Z, Wang J, Shang R, Zhou L, Wang X, Duan J, Ruan B, Gao Y, Dai B, et al: microRNA-150 suppresses cell proliferation and metastasis in hepatocellular carcinoma by inhibiting the GAB1-ERK axis. Oncotarget 7: 11595-11608, 2016.

35. Ito M, Teshima K, Ikeda S, Kitadate A, Watanabe A, Nara M, Yamashita J, Ohshima K, Sawada K and Tagawa H: MicroRNA-150 inhibits tumor invasion and metastasis by targeting the chemokine receptor CCR6, in advanced cutaneous T-cell lymphoma. Blood 123: 1499-1511, 2014.
36. Ma Y, Zhang P, Wang F, Zhang H, Yang J, Peng J, Liu W and Qin H: miR-150 as a potential biomarker associated with prognosis and therapeutic outcome in colorectal cancer. Gut 61: 1447-1453, 2012.

37. Srivastava SK, Bhardwaj A, Singh S, Arora S, Wang B, Grizzle WE and Singh AP: MicroRNA-150 directly targets MUC4 and suppresses growth and malignant behavior of pancreatic cancer cells. Carcinogenesis 32: 1832-1839, 2011.

38. Wuerkenbieke D, Wang J, Li Y and Ma C: miRNA-150 downregulation promotes pertuzumab resistance in ovarian cancer cells via AKT activation. Arch Gynecol Obstet 292: 1109-1116, 2015.

39. Stamatopoulos B, Van Damme M, Crompot E, Dessars B, Housni HE, Mineur P, Meuleman N, Bron D and Lagneaux L: Opposite prognostic significance of cellular and serum circulating MicroRNA-150 in patients with chronic lymphocytic leukemia. Mol Med 21: 123-133, 2015.

40. Yin QW, Sun XF, Yang GT, Li XB, Wu MS and Zhao J: Increased expression of microRNA-150 is associated with poor prognosis in non-small cell lung cancer. Int J Clin Exp Pathol 8: 842-846, 2015.

41. Wu Q, Jin H, Yang Z, Luo G, Lu Y, Li K, Ren G, Su T, Pan Y, Feng B, et al: MiR-150 promotes gastric cancer proliferation by negatively regulating the pro-apoptotic gene EGR2. Biochem Biophys Res Commun 392: 340-345, 2010.

42. Croce CM: Causes and consequences of microRNA dysregulation in cancer. Nat Rev Genet 10: 704-714, 2009.

43. Summy JM and Gallick GE: Src family kinases in tumor progression and metastasis. Cancer Metastasis Rev 22: 337-358, 2003.

44. Yang F, Luo LJ, Zhang L, Wang DD, Yang SJ, Ding L, Li J, Chen D, Ma R, Wu JZ and Tang JH: MiR-346 promotes the biological function of breast cancer cells by targeting SRCIN1 and reduces chemosensitivity to docetaxel. Gene 600: 21-28, 2017. 